\title{
Design and Implementation of a Novel Self-adaptive Fuzzy Logic Controller for a $\mathrm{pH}$ Neutralization Process
}

\author{
Walter Nsengiyumva and Xueyong Chen ${ }^{*}$ \\ Fujian Agriculture and Forestry University, College of Mechanical and Electronic Engineering, 15 Shangxia Dian Rd, Cangshan \\ District, 350002 Fuzhou, Fujian, China. \\ ${ }^{*}$ Corresponding Author
}

\begin{abstract}
This paper presents a self-adaptive fuzzy logic controller for a $\mathrm{pH}$ neutralization process which has been designed and implemented in real time process. The controller deals with the minimization of both the steady state error and time taken to reach steady state under varying operating conditions. The interesting fact about this control technique is that it operates a full-scale $\mathrm{pH}$ neutralization plant using the same equipment like that in real time full-scale industrial $\mathrm{pH}$ neutralization plant. The proposed self-adaptive technique updates the control parameters and the normalized universe of discourse of output fuzzy membership functions using varying scaling factors based on error and change of error values. A combination of both the coarse control and fine control was used for the overall control action. The speed of the response of the self-adaptive controller is handled by the coarse control technique while the amount of deviation of the measured values with respect to the setpoint under steady state is handled by the fine control technique. The performance of the envisaged selfadaptive scheme is tested for $\mathrm{pH}$ control in real time, and results are encouraging. MATLAB ${ }^{\mathrm{TM}}$ SIMULINK ${ }^{\mathrm{TM}}$ software is used for control, display as well as online communication with the DCS system through an OPC server configured on a PC. The controller is easily implementable and user-friendly and can, therefore, be adopted by process engineers. Lastly, the control technique envisaged herein can be implemented on preexisting control loops, hence alleviating financial constraints and great savings benefits of the controller.
\end{abstract}

Keywords-pH control; neutralization process; self-adaptive control; nonlinear process; fuzzy logic control; online control

\section{INTRODUCTION}

The control of $\mathrm{pH}$ neutralization processes is one of the most challenging problems in process industries today [1]. The time-varying nature of the neutralization process makes $\mathrm{pH}$ a moving target whose accurate control is almost impossible to achieve [2-4]. Moreover, both the steady-state and dynamic properties of the $\mathrm{pH}$ neutralization process are not linear which makes $\mathrm{pH}$ a benchmark problem often used by many researchers and engineers to define nonlinear model structures and control methods [5]. Process industries such as food and beverage processing, biotechnology, pharmaceutical, metal refineries, wastewater treatment and thermal power plants run several operations where both the $\mathrm{pH}$ monitoring and control are critical [6]. Most of these operations are performed to ensure both the standard quality products and the environmental requirements are not jeopardized [7]. Although $\mathrm{pH}$ control is known to be a deterrent problem for all the aforementioned industries, its industrial significance makes it a fascinating subject for many researchers and engineers and has therefore received considerable attention in recent years $[3$, $5,6]$.

Equally important, the inherent nonlinearity characteristics of $\mathrm{pH}$ neutralization makes it inadequate to control using classical linear controllers such as PID and all its derivatives; especially when the setpoint and/or any other operating conditions are constantly changing. In light of these, studies [8] argued that adaptive control based techniques may be used for greater control results. Early works on $\mathrm{pH}$ control featuring adaptive control techniques used dynamic process models, which were developed based on first-principle approaches such as laws of conservation, physical and chemical laws, reaction invariants, and strong acid equivalent [9-14]. Many other adaptive controllers with nonlinear features were later developed following the works done by the previous authors [2]. These types of controllers included but were not limited to an adaptive nonlinear output feedback control technique featuring both an input-output linearizing controller and a nonlinear observer [15], an adaptive nonlinear controller using fuzzy approximators [16], an adaptive backstepping state feedback controller [17] and an adaptive nonlinear internal model controller [18] to name but few. Other conventional adaptive controllers such as gain-scheduling [19], adaptive fuzzy sliding mode controller [20], model reference adaptive control [21] and self-tuning regulators [22] with advanced identification and control techniques were also used.

The recent advancements in modern control systems and computer technology have led to the development of model predictive control techniques whereby a dynamic model of the controlled process is used directly online [23]. During the control action of the model predictive controller (MPC), the model computes predictions of the output/state variables which are then used during optimization of the control sequence [4]. To this end, a significant number of MPCs featuring nonlinear and comprehensive process models for process prediction and optimization were developed $[3,6]$. These included nonlinear model predictive controllers based on Hammerstein [24, 25], Wiener [26, 27], Laguerre Polynomial Techniques [28, 29], Volterra Series [6, 30] and Artificial Neural Networks [31, 32] among others. 
Nevertheless, the ability of the $\mathrm{pH}$ dynamic model to replicate the actual nonlinear behavior of neutralization processes prevailed and this limited both the accuracy and ability of most of the $\mathrm{pH}$ controllers proposed up-to-date [3]. The fundamental step in developing a nonlinear MPC is to essentially designate an appropriate structure of a nonlinear model that accurately identifies the system dynamics $[6,23]$. However, the main disadvantage of the nonlinear modeling is that using a nonlinear model often leads to a complex dynamic model that is almost impossible to use in the nonlinear predictive control. Furthermore, nonlinear modeling often changes the control problem of the nonlinear MPC from convex quadratic programming to a nonconvex nonlinear case which not only is it even more difficult to handle but it also does not often guarantee the global optimum [33, 34].

As an alternative procedure to overcome $\mathrm{pH}$ processes' inherent nonlinearity and time-varying nature, few researchers suggested the use of model-free intelligent controllers. In 2007, Syafiie et al. [35] proposed a model-free controller using reinforcement learning. An earlier study by Syafiie et al. [36] equally presented a macro-actions in model-free intelligent control while Zheng and Wang [37] suggested a model-free control based on neural networks. Although no direct comparison was made to determine which of the advanced/intelligent controllers provided greater performances in terms of $\mathrm{pH}$ monitoring and control, Rose et al. [38] alleged that Fuzzy Logic controllers are, however, less demanding visà-vis its hardware requirements and other implementation tools. It is important to remember that the fuzzy logic control is based on the intelligent methodology of human thinking and decision making mechanisms which ultimately mimic the problem-solving capabilities of a more skillful operator [3]. Following the aforementioned, adaptive control technique with fuzzy logic has been used to investigate its setpoint tracking and disturbances rejection capabilities for a $\mathrm{pH}$ neutralization process and results were encouraging [39]. The same type of controller was equally used as an estimator for an adaptive model-based control framework [16], as well as both as a self-adapting and a self-organizing mechanisms operator [40, 41]. Nevertheless, a fuzzy logic controller featuring adaptive mechanism is not easy to build, hence an effective control performance for multiple $\mathrm{pH}$ regions is very hard to achieve.

Moreover, similar studies [4, 16] on $\mathrm{pH}$ monitoring and control pointed out that there are always a number of difficulties associated with the currently available $\mathrm{pH}$ control techniques. For example, designs often need state variables for implementation (such as feedback linearization technique), which are usually not available in practice. Others designs are practical but yet very complex and require time-consuming computations leading to slow responses and hence the inability of the controller to track both the setpoint changes and disturbances encumbering the process. Other types of controllers require more sophisticated hardware that is very expensive and not easy to afford by small companies and process owners with limited financial capabilities. Lastly, several control techniques require a significant number of tuning parameters which makes their application quite impractical. As such, designing a control scheme without the aforementioned drawbacks for $\mathrm{pH}$ control is ultimately encouraged. In this paper, an online application of a novel fuzzy logic controller (FLC) featuring a self-adaptive $\mathrm{pH}$ control technique of a strong acid-strong base neutralization process has been proposed.

\section{DESCRIPTION OF THE PH NEUTRALIZATION STUDY PLANT}

The control of $\mathrm{pH}$ is important in many process industries in which tight control of several variables is sought to meet the quality standard products and ensure the environmental legislations are not jeopardized. $\mathrm{pH}$ control is recognized as a challenging assignment because of the time-varying behavior exhibited by the neutralization process. The later experiences both rapid and spectacular transitions within the control channel which lead to remarkable changes in process gain over a small range of $\mathrm{pH}$. Moreover, automatic $\mathrm{pH}$ controllers have to contend with the inevitable process disturbances, incorrect valve sizing and in some cases poorly designed processes. All the aforementioned challenges can be so severe that it is often impossible to handle $\mathrm{pH}$ control using classical linear types of controllers. Therefore, a properly designed process plant with adequate equipment is to ultimately be sought for, in order to alleviate some of the burdens to the $\mathrm{pH}$ control systems designs. For the purpose of this study, an actual full-scale $\mathrm{pH}$ neutralization study plant was designed and implemented. The particularity with this plant is that it uses the same type of equipment as that used in the industrial neutralization plant. Henceforth, results from this study may directly be applied to any full-scale $\mathrm{pH}$ neutralization process plant.

\section{A. pH Neutralization Reactor of the Study Plant}

A detailed process and instrumentation diagram (P\&ID) of the $\mathrm{pH}$ neutralization plant subjected to this study is depicted in Figure I. The acid and alkaline are pumped to the continuously stirred tank reactor (CSTR) via a pair of centrifugal pumps (MP-105R) PMP101 and PMP102 respectively. The concentrations of acid and alkaline are denoted by $\mathrm{Ca}$ and $\mathrm{Cb}$ respectively. A pair of conductivity sensors (LENSHER/LN-WC) and flowmeters (LWGY-A) are also mounted inline, and each pair (flowmeter and conductivity sensor) is used to determine the concentration levels of the acid and alkaline solutions respectively. The system also features four electrical flow control valves (P1C11U101025), two of which regulate the required amount of acid and alkaline into the CSTR during the neutralization process. Lastly, a pair of $\mathrm{pH}$ probes is used for $\mathrm{pH}$ measurements, one for CSTR and another one for the final product storage tank respectively. The outlet flow of the CSTR effluent is controlled by an electrical control valve which maintains a steady level in the tank at desired $\mathrm{pH}$ setpoint. The CSTR effluent is directed to the final product storage tank for an eventual discharge, and a portion of the CSTR effluent is reverted back to the CSTR to assist for a perfect mixing of the solution under titration during the control experiments. 


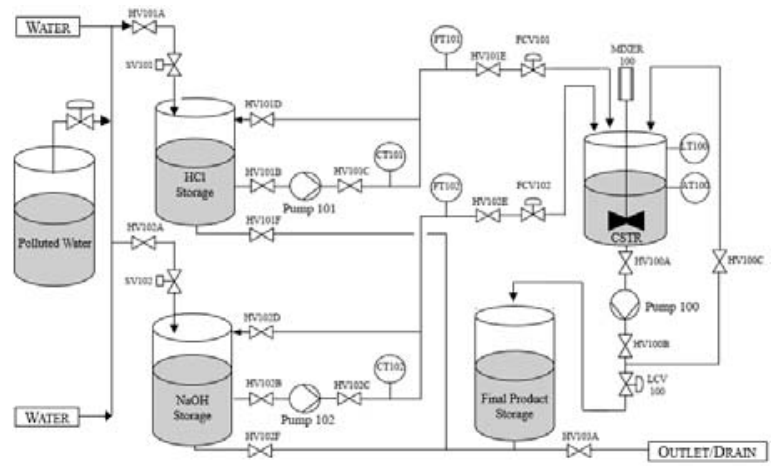

FIGURE I. DETAILED P\&ID OF THE STUDY PH NEUTRALIZATION PLANT

The nominal speed of pumps PMP101 and PMP102 denoted $\mathrm{Sa}$ and $\mathrm{Sb}$ respectively, varies between $0-100 \%$, but they are all set to operate on demand to different speeds between $20-80 \%$ of their maximum speed. All flow control valves (FCV) on the plant are controlled by a 4-20 mA current loop from fully closed $(0 \%)$ to fully open $(100 \%)$ states. The $\mathrm{pH}$ probe (YS8166B) was calibrated using $\mathrm{pH}$ buffer solutions of 4.0, 6.85 and 9.18 to ensure a linear relationship between sensors' operating voltage and the resulting $\mathrm{pH}$ values. A brief description of the nominal operating conditions/settings for the study plant is highlighted in Table I.

TABLE I. PH NEUTRALIZATION PLANT PARAMETER

\begin{tabular}{|l|l|}
\hline Parameters & Values \\
\hline The volume of the tank $(\mathrm{V})$ & 100 Liters \\
Steady state level of the CSTR & $60 \%$ \\
pH setpoint settings & 7 \\
The concentration of $\mathrm{NaOH}(\mathrm{Cb})$ & $3.25 \times 10^{-3} \mathrm{~mol} / \mathrm{L}$ \\
The concentration of $\mathrm{HCl}(\mathrm{Ca})$ & $3.87 \times 10^{-3} \mathrm{~mol} / \mathrm{L}$ \\
Steady state speed of pumps & $40 \%$ \\
The voltage of the pH sensors & $0-5 \mathrm{~V}$ \\
Equivalent pH readings & $0.2-13.4$ \\
Control valves opening ranges & $10-100 \%$ \\
\hline
\end{tabular}

\section{B. $p H$ Process Control Hardware and Software}

Delta PLC (DVP16ES2) control hardware was used in the real-time control of the process plant and connected to an Intel-Core i5 PC with 8GB of RAM running MATLAB ${ }^{\mathrm{TM}}$ OPC TOOLBOX ${ }^{\mathrm{TM}}$ and WPLSoft ${ }^{\mathrm{TM}}$ programming software. An Open Process Control (OPC) server was established to transfer data bi-directionally from the Distributed Control System (DCS) to MATLAB ${ }^{\text {TM }}$ SIMULINK ${ }^{\mathrm{TM}}$. The proposed controller is designed in MATLAB ${ }^{\mathrm{TM}}$ and transmitted to the DCS in real time as depicted in Figure II. One of the advantages of this configuration is that it allows for an easy implementation of the self-adaptive FLC on an external platform without interrupting the background computations performed by DCS and the subsequent control of the process underway.

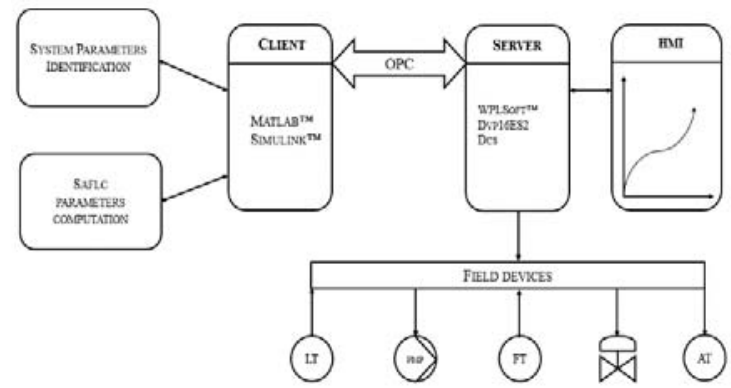

FIGURE II. GENERAL LAYOUT OF CONNECTIONS BETWEEN MATLAB $^{\text {TM }}$ AND DCS USING OPC SERVER

\section{CONTROLLER DESIGN AND ITS REAL-TIME IMPLEMENTATION ON THE SYSTEM}

This study focusses on the design and implementation of a self-adaptive FLC of a $\mathrm{pH}$ neutralization process. This controller is based on Mamdani fuzzy inference system (FIS) and uses $\mathrm{e}^{*}(\mathrm{t})$ and $\delta \mathrm{e}^{*}(\mathrm{t})$ for its inputs which are the normalized values of the error $(\delta \mathrm{e})$ and the change of error $(\delta \mathrm{e})$ respectively. Assuming $\mathrm{pH} 0$ is the preset value of $\mathrm{pH}, \mathrm{t}$ the sampling time, $\alpha$ and $\beta$ scaling factors of e and $\delta$ e, the values of $\mathrm{e}^{*}(\mathrm{t})$ and $\delta \mathrm{e}^{*}(\mathrm{t})$ can be obtained from the following equations.

$$
\mathrm{e}^{*}(\mathrm{t})=\alpha[\mathrm{e}(\mathrm{t})]=\alpha\left[\mathrm{pH}_{0}-\mathrm{pH}(\mathrm{t})\right]
$$

and;

$$
\delta \mathrm{e}^{*}(\mathrm{t})=\beta\left[\delta \mathrm{e}^{*}(\mathrm{t})\right]=\beta[\mathrm{e}(\mathrm{t})-\mathrm{e}(\mathrm{t}-1)]
$$

The instantaneous normalized change of the output of the proposed self-adaptive FLC is denoted $\zeta^{*}(\mathrm{t})$. The normalized membership functions for both input variables $\left(\mathrm{e}^{*}, \delta \mathrm{e}^{*}\right)$ and output variable $\left(\zeta^{*}\right)$ are shown in Figure III and Figure IV respectively. The rule base for empirical values of these two parameters, i.e. input and output variables, are is also indicated in Table II.

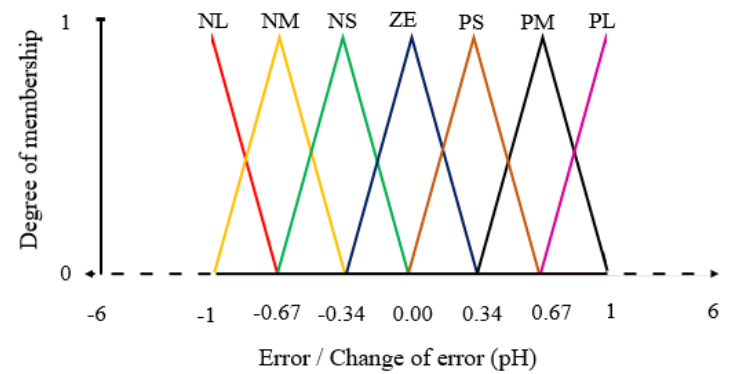

FIGURE III. NORMALIZED FUZZY LOGIC INPUTS MEMBERSHIP FUNCTIONS 


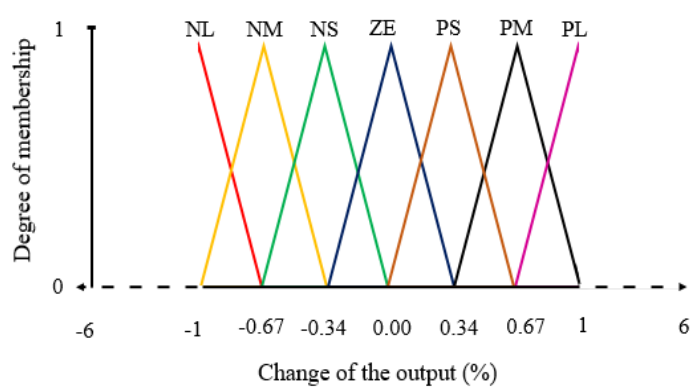

FIGURE IV. NORMALIZED FUZZY LOGIC OUTPUT MEMBERSHIP FUNCTIONS

TABLE II. UNIVERSAL TABLE OF THE FUZZY RULE BASE

\begin{tabular}{|l|l|l|l|l|l|l|l|}
\hline \multirow{2}{*}{$\begin{array}{c}\text { Error } \\
(\mathbf{e})\end{array}$} & \multicolumn{7}{|c|}{ Change of error (8e) } \\
\cline { 2 - 8 } & $\mathrm{NL}$ & $\mathrm{NM}$ & $\mathrm{NS}$ & $\mathrm{ZE}$ & $\mathrm{PS}$ & $\mathrm{PM}$ & $\mathrm{PL}$ \\
\hline $\mathrm{NL}$ & $N L$ & $N L$ & $N L$ & $N L$ & $N M$ & $N S$ & $Z E$ \\
\hline $\mathrm{NM}$ & $N L$ & $N L$ & $N L$ & $N M$ & $N S$ & $Z E$ & $P S$ \\
\hline NS & $N L$ & $N L$ & $N M$ & $N S$ & $Z E$ & $P S$ & $P M$ \\
\hline ZE & $N L$ & $N M$ & $N S$ & $Z E$ & $P S$ & $P M$ & $P L$ \\
\hline PS & $N M$ & $N S$ & $Z E$ & $P S$ & $P M$ & $P L$ & $P L$ \\
\hline PM & $N S$ & $Z E$ & $P S$ & $P M$ & $P L$ & $P L$ & $P L$ \\
\hline PL & $Z E$ & $P S$ & $P M$ & $P L$ & $P L$ & $P L$ & $P L$ \\
\hline
\end{tabular}

For a nonlinear process such as $\mathrm{pH}$ neutralization, the FLC must be optimized for greater performance. However, operating conditions of the $\mathrm{pH}$ neutralization process always change with time which makes its control techniques challenging and ultimately hungry for repeated application of optimization procedures. A self-adaptive mechanism allows adaptive FLC to modify its input and/or output scaling factors to adapt to the changes occurring in the operating conditions. In this paper, a novel self-adaptive FLC is designed and implemented as presented in Figure V.

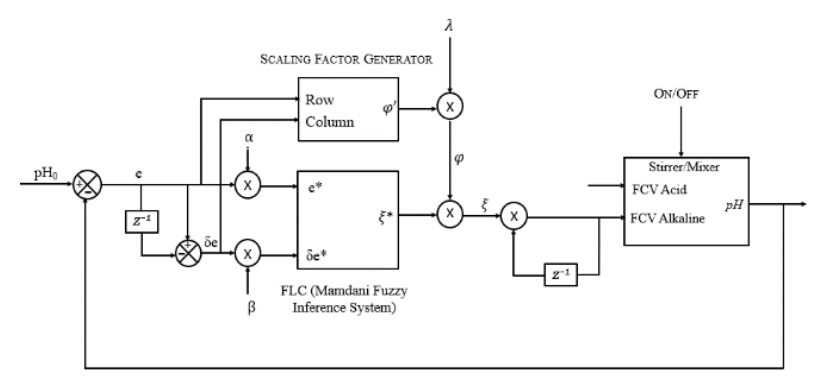

FIGURE V. LOGICAL DIAGRAM OF A SELF-ADAPTIVE FUZZY LOGIC CONTROLLER

The instantaneous output scaling factor $\varphi^{\prime}$ is obtained from Table III. Input variables e and $\delta$ e are divided into seven identical intervals namely: e $0, \delta \mathrm{e} 0 \in[-6,-1[; \mathrm{e} 1, \delta \mathrm{e} 1 \in[-1,-$ $0.5[$; e $2, \delta \mathrm{e} 2 \in[-0.5,-0.1[; \mathrm{e} 3, \delta \mathrm{e} 3 \in[-0.1,0.1[; \mathrm{e} 4, \delta \mathrm{e} 4 \in$ $[0.1,0.5[;$ e $5, \delta \mathrm{e} 5 \in[0.5,1[; \mathrm{e} 6, \delta \mathrm{e} 6 \in[1,6]$. As can be seen from the entries of the Table III, $\varphi^{\prime}$ has been assigned a larger value if $\mathrm{pH}$ is away from $\mathrm{pH}_{0}$ and vice versa. Throughout our experiments, it was noticed that a large value of $\varphi^{\prime}$ decreases the settling time when $\mathrm{pH}$ significantly differs from $\mathrm{pH}_{0}$ whereas a small value of $\varphi^{\prime}$ allows for a steady state response within settling band when $\mathrm{pH}$ is near $\mathrm{pH}_{0}$. Therefore, all the entries of Table III confirm the concurrent use of both the coarse and fine control techniques to reach the required control values of $\mathrm{pH}$ faster and accurately than most of the available $\mathrm{pH}$ controllers on a full scale $\mathrm{pH}$ plant.

\section{TABLE III. DETERMINATION OF THE SCALING FACTOR $\Phi$ '}

\begin{tabular}{|l|l|l|l|l|l|l|l|}
\hline $\begin{array}{c}\text { Range } \\
\text { Error } \\
(\mathbf{e})\end{array}$ & \multicolumn{6}{|c|}{ The range for the change of error (ce) } \\
\cline { 2 - 8 } & $\delta e 0$ & $\delta e 1$ & $\delta e 2$ & $\delta e 3$ & $\delta e 4$ & $\delta e 5$ & $\delta e 6$ \\
\hline$e 0$ & 10 & 10 & 10 & 10 & 8 & 6 & 4 \\
\hline$e 1$ & 10 & 10 & 10 & 8 & 6 & 4 & 6 \\
\hline$e 2$ & 10 & 10 & 8 & 6 & 4 & 6 & 8 \\
\hline$e 4$ & 10 & 8 & 6 & 4 & 6 & 8 & 10 \\
\hline$e 5$ & 8 & 6 & 4 & 6 & 8 & 10 & 10 \\
\hline$e 5$ & 6 & 4 & 6 & 8 & 10 & 10 & 10 \\
\hline$e 6$ & 4 & 6 & 8 & 10 & 10 & 10 & 10 \\
\hline
\end{tabular}

\section{RESUlTS AND Discussions}

The proposed control algorithm involves two parts for sequential execution viz. process initialization and the subsequent control action by the self-adaptive fuzzy controller. Two $\mathrm{pH}$ boundaries $(4-10)$ are defined by the user as the initial control values depending on the preliminary knowledge of the sample viz. the lower bound $\mathrm{pH}\left(\mathrm{pH}_{\mathrm{L}}\right)$ and the upper bound $\mathrm{pH}\left(\mathrm{pH}_{\mathrm{U}}\right)$. The above step is termed initialization and is only meant to establish the controller's range of operation. During the initialization process, the system checks if the initial measured value of $\mathrm{pH}$ is within the aforementioned boundaries depending of the sample under consideration (either acid or alkaline process stream) before proceeding to the control action. After the control action was completed, transient characteristics of the proposed self-adaptive FLC were computed to evaluate its performance. These transient characteristics include the percentage of overshoot (OVS), the peak time (PT), the rise time (RT), the settling time (ST) and the integral of absolute error (IAE). Table 4 shows the values of all the aforementioned transient characteristics for different values of both the inputs normalizing factors $(\alpha$ and $\beta)$ and the controller's output scaling factor multiplier $(\lambda)$.

TABLE IV. PERFORMANCE SUMMARY OF THE PROCESS RESPONSE WITH DIFFERENT LEVELS OF THE CONTROLLER'S SCALING FACTOR MULTIPLIER $(\Lambda)$ AT DIFFERENT PH LEVELS OF THE SAMPLE

\begin{tabular}{|c|c|c|c|c|c|c|}
\hline Case study & $\lambda$ & OVS & PT & RS & ST & IAE \\
\hline \multirow{4}{*}{$\begin{array}{l}\text { The pH is } \\
\text { acidic }\end{array}$} & 1 & 29.4 & 73 & 18 & 123 & 126.6 \\
\hline & 2 & 24.1 & 53 & 15 & 158 & 138.7 \\
\hline & 3 & 22.6 & 56 & 14 & 314 & 274.8 \\
\hline & 4 & 15.1 & 98 & 42 & - & 497.3 \\
\hline \multirow{4}{*}{$\begin{array}{l}\text { The pH is } \\
\text { alkaline }\end{array}$} & 1 & 27.2 & 82 & 45 & 156 & 130.3 \\
\hline & 2 & 28.8 & 79 & 51 & 171 & 219.1 \\
\hline & 3 & 29.5 & 71 & 62 & 190 & 229.6 \\
\hline & 4 & 27.4 & 67 & 72 & 341 & 830.5 \\
\hline
\end{tabular}

Graphical performance comparison in terms of $\mathrm{pH}$ response and opening percentage of FCV have been shown in Figure VI, Figure VII respectively for cases 1 to 4 for an acidic process stream titrated with an alkaline stream (manipulated stream). Similarly, the same results were reported in Figure VIII and IX for an alkaline process stream 
titrated with and acidic stream (manipulated stream).

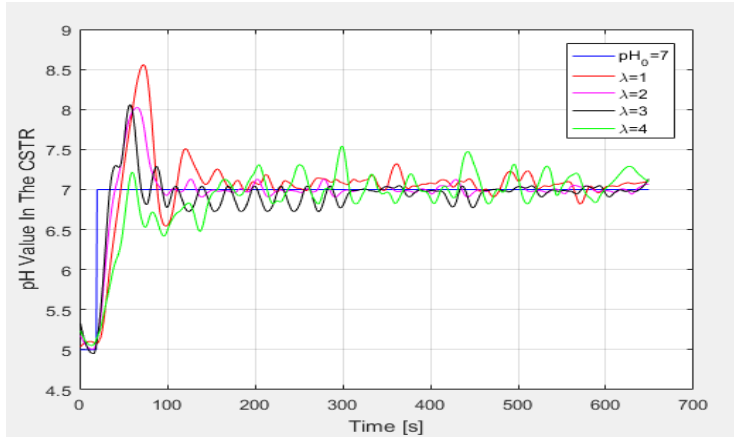

FIGURE VI. GRAPHICAL PERFORMANCE COMPARISON OF THE PH RESPONSES AT DIFFERENT VALUES OF $\Lambda$ USING ACID PROCESS STREAM AND AN ALKALINE MANIPULATED STREAM

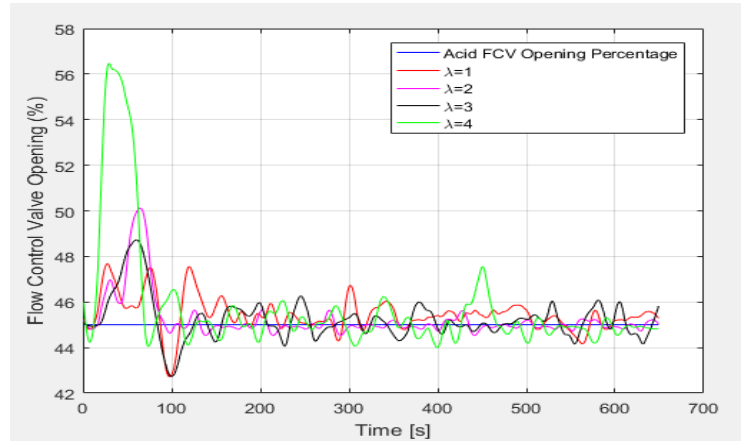

FIGURE VII. GRAPHICAL PERFORMANCE COMPARISON OF THE ALKALINE FCV OPENING PERCENTAGE AT DIFFERENT VALUES OF $\Lambda$ USING ACID PROCESS STREAM AND AN ALKALINE MANIPULATED STREAM

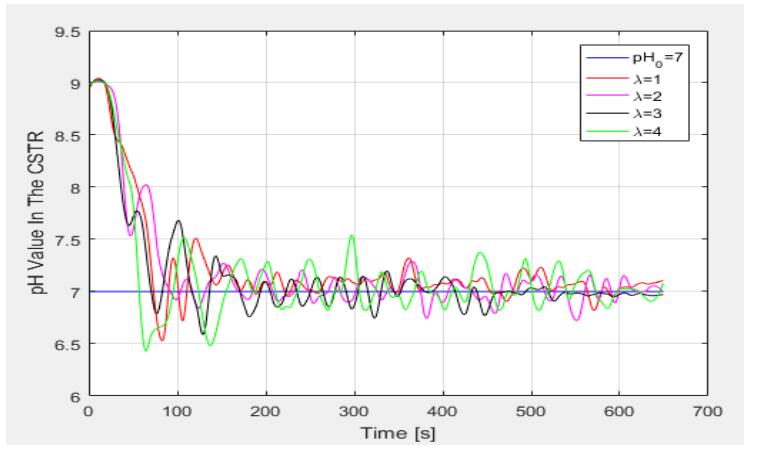

FIGURE VIII. GRAPHICAL PERFORMANCE COMPARISON OF THE PH RESPONSE AT DIFFERENT VALUES OF $\Lambda$ USING ALKALINE PROCESS STREAM AND AN ACIDIC MANIPULATED STREAM

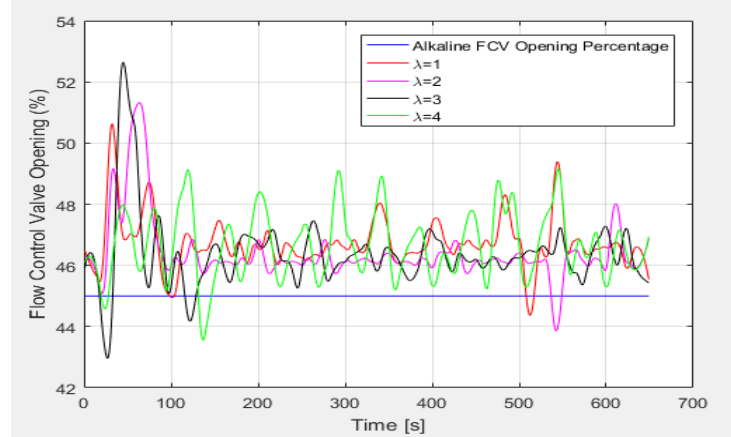

FIGURE IX. GRAPHICAL PERFORMANCE COMPARISON OF THE ACID FCV OPENING PERCENTAGE AT DIFFERENT VALUES OF $\Lambda$ USING ALKALINE PROCESS STREAM AND AN ACIDIC MANIPULATED STREAM

In the light of Table IV above and the subsequent graphical performance comparison in terms of $\mathrm{pH}$ response, pumps speeds ( $\mathrm{Sa}$ and $\mathrm{Sb}$ ) as well as FCV opening percentage when dealing with different solutions, the following conclusions can be drawn.

(a) The speed of the controller and the subsequent $\mathrm{pH}$ response is directly proportional to the value of the scaling factor multiplier $\lambda$. This means that the $\mathrm{pH}$ response is faster for bigger values of than it is for their smaller counterparts.

(b) It was noticed that a greater value ofprovides better control results when dealing with an acidic process stream titrated with alkaline manipulated stream than its alkaline counterpart.

(c) Experiments have shown that the values of $e$ and $\delta e$ reach high values when they are at their mid intervals, i.e., $e 2$, $e 2, e 4$ and $\delta e 2, \delta e 3, \delta e 4$ respectively. This means that the amplification of is also high at these values, and hence a faster $\mathrm{pH}$ response is observed for the aforementioned intervals than in any other areas of the control action.

(d) The size of the first overshoot is inversely proportional to the value of $\lambda$, i.e., the bigger the value of $\lambda$, the smaller the size of the first overshoot of the $\mathrm{pH}$ response and vice-versa.

(e) The obtained $\mathrm{pH}$ results show that the $\mathrm{pH}$ response continuously remains within settling band for smaller values of $\lambda(1,2,3)$ than it is for greater values of $\lambda(4)$.

(f) In alkaline process streams, the bigger value of $\lambda$, i.e., $\lambda=4$ was found to be pushing the $\mathrm{pH}$ response outside of the settling band $(7 \pm 0.2)$ and hence a conclusion was made as to keep the value of $\lambda=1,2$ or 3 for greater control results in alkaline process streams.

Interesting facts about this controller were also observed where it showed greater $\mathrm{pH}$ controlling capabilities. For the scaling factor's multiplier $\lambda=4, \mathrm{pH}$ response tends to go unbound, but the self-adaptive feature of the fuzzy logic controller comes in and immediately adjusts the value of $\varphi$ to bring the $\mathrm{pH}$ response back to the desired settling band. Experiments conducted herein have confirmed that large values of $\varphi$ decreases the settling time when $\mathrm{pH}$ significantly differs from $\mathrm{pH}_{0}$ whereas small values of $\varphi$ allow for a steady 
state response within settling band when $\mathrm{pH}$ is near $\mathrm{pH}_{0}$ and hence the application of both coarse and fine control techniques. Lastly, greater values of $\varphi$ produces smaller overshoot, faster response and reduced settling the time which guarantees an optimum control of the $\mathrm{pH}$ neutralization that was the subject of our study.

\section{CONCLUSION AND FutURE OUTLOOK}

The proposed self-adaptive fuzzy logic controller has been implemented on a full-scale industrial $\mathrm{pH}$ neutralization plant. The online signal processing was performed by MATLAB ${ }^{\mathrm{TM}}$ SIMULINK ${ }^{\mathrm{TM}}$ communicating with WPLSoft ${ }^{\mathrm{TM}}$ and DCS through an OPC server configured on Intel-Core i5 PC. The self-adaptive controller has been investigated for $\mathrm{pH}$ setpoint tracking capabilities; first from 5 to 7 and then from 9 to 7 . The resulting control action of the prosed controller achieves both the desired $\mathrm{pH}$ response values and the settling within a band in a reasonable amount of time. In cases where the controlled variable of $\mathrm{pH}$ overshoots/undershoots the setpoint, the self-adaptive controller regulated its output universe of discourse and brought the $\mathrm{pH}$ response back to the desired settling band. The proposed self-adaptive fuzzy logic controller was found to provide higher speed $\mathrm{pH}$ responses, less deviation from setpoint and better settling within the desired band for greater values of its scaling factor. Equally important, the simplicity of this novel self-adaptive controller is an attractive feature for its adaptation by process engineers in this field to get greater $\mathrm{pH}$ control results. Moreover, existing control loops within the process plant can still be utilized and hence an added financial savings with greater results.

\section{ACKNOWLEDGMENT}

The financial support from Fujian Agriculture and Forestry University (College of Mechanical and Electronic Engineering) through the university's research fund is greatly acknowledged.

\section{REFERENCES}

[1] H. Alvarez, C. Londoño, F. Di Sciascio, and R. Carelli, "pH neutralization process as a benchmark for testing nonlinear controllers," Industrial \& engineering chemistry research, vol. 40, pp. 2467-2473, 2001 .

[2] A. Nejati, M. Shahrokhi, and A. Mehrabani, "Comparison between backstepping and input-output linearization techniques for $\mathrm{pH}$ process control," Journal of Process Control, vol. 22, pp. 263-271, 2012.

[3] P. K. Singh, S. Bhanot, H. K. Mohanta, and V. Bansal, "Self-tuned fuzzy logic control of a $\mathrm{pH}$ neutralization process," IEEE 21st International Conference on Automation and Computing (ICAC), pp. 16, 2015.

[4] M. Ławryńczuk, "Modelling and predictive control of a neutralisation reactor using sparse support vector machine Wiener models," Neurocomputing, vol. 205, pp. 311-328, 2016.

[5] Z. Zou, M. Yu, Z. Wang, X. Liu, Y. Guo, F. Zhang, et al., "Nonlinear Model Algorithmic Control of a pH Neutralization Process," Chinese Journal of Chemical Engineering, vol. 21, pp. 395-400, 2013.

[6] A. Hermansson and S. Syafiie, "Model predictive control of $\mathrm{pH}$ neutralization processes: a review," Control Engineering Practice, vol. 45, pp. 98-109, 2015.

[7] R. Ibrahim, "Practical modelling and control implementation studies on a pH neutralization process pilot plant," University of Glasgow, 2008.
[8] A. Loh, K. Looi, and K. Fong, "Neural network modelling and control strategies for a $\mathrm{pH}$ process," Journal of Process Control, vol. 5, pp. 355362,1995

[9] T. J. McAvoy, E. Hsu, and S. Lowenthal, "Dynamics of $\mathrm{pH}$ in controlled stirred tank reactor," Industrial \& Engineering Chemistry Process Design and Development, vol. 11, pp. 68-70, 1972.

[10] T. J. McAvoy, "Time optimal and Ziegler-Nichols control. Experimental and theoretical results," Industrial \& Engineering Chemistry Process Design and Development, vol. 11, pp. 71-78, 1972.

[11] T. K. Gustafsson and K. V. Waller, "Dynamic modeling and reaction invariant control of $\mathrm{pH}, "$ Chemical Engineering Science, vol. 38, pp. 389-398, 1983.

[12] T. K. Gustafsson, "An experimental study of a class of algorithms for adaptive $\mathrm{pH}$ control," Chemical engineering science, vol. 40, pp. 827 $837,1985$.

[13] R. A. Wright and C. Kravaris, "Nonlinear control of $\mathrm{pH}$ processes using the strong acid equivalent," Industrial \& Engineering Chemistry Research, vol. 30, pp. 1561-1572, 1991.

[14] R. A. Wright, M. Soroush, and C. Kravaris, "Strong acid equivalent control of pH processes: an experimental study," Industrial \& engineering chemistry research, vol. 30, pp. 2437-2444, 1991.

[15] M. A. Henson and D. E. Seborg, "Adaptive nonlinear control of a $\mathrm{pH}$ neutralization process," IEEE transactions on control systems technology, vol. 2, pp. 169-182, 1994.

[16] S. Salehi, M. Shahrokhi, and A. Nejati, "Adaptive nonlinear control of $\mathrm{pH}$ neutralization processes using fuzzy approximators," Control Engineering Practice, vol. 17, pp. 1329-1337, 2009.

[17] S. S. Yoon, T. W. Yoon, D. R. Yang, and T. S. Kang, "Indirect adaptive nonlinear control of a $\mathrm{pH}$ process," Computers \& chemical engineering, vol. 26, pp. 1223-1230, 2002

[18] N. L. Narayanan, P. Krishnaswamy, and G. Rangaiah, "An adaptive internal model control strategy for $\mathrm{pH}$ neutralization," Chemical Engineering Science, vol. 52, pp. 3067-3074, 1997.

[19] R. H. Nyström, B. M. Åkesson, and H. T. Toivonen, "Gain-scheduling controllers based on velocity-form linear parameter-varying models applied to an example process," Industrial \& engineering chemistry research, vol. 41, pp. 220-229, 2002.

[20] J. Chen, Y. Peng, W. Han, and M. Guo, "Adaptive fuzzy sliding mode control in PH neutralization process," Procedia Engineering, vol. 15, pp. 954-958, 2011.

[21] M. C. Palancar, J. M. Aragon, J. A. Miguéns, and J. S. Torrecilla, "Application of a model reference adaptive control system to $\mathrm{pH}$ control. Effects of lag and delay time," Industrial \& engineering chemistry research, vol. 35, pp. 4100-4110, 1996.

[22] M. Alpbaz, H. Hapoğlu, G. Özkan, and S. Altuntaş, "Application of selftuning PID control to a reactor of limestone slurry titrated with sulfuric acid," Chemical Engineering Journal, vol. 116, pp. 19-24, 2006.

[23] D. Shaghaghi, A. Fatehi, and A. Khaki-Sedigh, "Multi-linear model set design based on the nonlinearity measure and H-gap metric," ISA transactions, 2017

[24] H. C. Park, S. W. Sung, and J. Lee, "Modeling of Hammerstein- Wiener Processes with Special Input Test Signals," Industrial \& engineering chemistry research, vol. 45, pp. 1029-1038, 2006.

[25] K. Fruzzetti, A. Palazoğlu, and K. McDonald, "Nolinear model predictive control using Hammerstein models," Journal of process control, vol. 7, pp. 31-41, 1997.

[26] S. J. Norquay, A. Palazoglu, and J. A. Romagnoli, "Application of Wiener model predictive control (WMPC) to a $\mathrm{pH}$ neutralization experiment," IEEE Transactions on Control Systems Technology, vol. 7, pp. 437-445, 1999.

[27] S. Oblak and I. Škrjanc, "Continuous-time Wiener-model predictive control of a $\mathrm{pH}$ process based on a PWL approximation," Chemical Engineering Science, vol. 65, pp. 1720-1728, 2010.

[28] S. Mahmoodi, J. Poshtan, M. R. Jahed-Motlagh, and A. Montazeri, "Nonlinear model predictive control of a $\mathrm{pH}$ neutralization process based on Wiener-Laguerre model," Chemical Engineering Journal, vol. 146, pp. 328-337, 2009. 
[29] Q. C. Wang and J.-z. Zhang, "Wiener model identification and nonlinear model predictive control of a $\mathrm{pH}$ neutralization process based on Laguerre filters and least squares support vector machines," Journal of Zhejiang University Science, vol. 12, pp. 25-35, 2011.

[30] R. Díaz-Mendoza and H. Budman, "Structured singular valued based robust nonlinear model predictive controller using Volterra series models," Journal of Process Control, vol. 20, pp. 653-663, 2010.

[31] Y.-K. Yeo and T.-I. Kwon, "A neural PID controller for the pH neutralization process," Industrial \& engineering chemistry research, vol. 38, pp. 978-987, 1999.

[32] B. M. Åkesson, H. T. Toivonen, J. B. Waller, and R. H. Nyström, "Neural network approximation of a nonlinear model predictive controller applied to a $\mathrm{pH}$ neutralization process," Computers \& chemical engineering, vol. 29, pp. 323-335, 2005.

[33] P. O. Scokaert, D. Q. Mayne, and J. B. Rawlings, "Suboptimal model predictive control (feasibility implies stability)," IEEE Transactions on Automatic Control, vol. 44, pp. 648-654, 1999.

[34] M. Ławryńczuk, "Suboptimal nonlinear predictive control based on multivariable neural Hammerstein models," Applied Intelligence, vol. 32, pp. 173-192, 2010.

[35] S. Syafiie, F. Tadeo, and E. Martinez, "Model-free learning control of neutralization processes using reinforcement learning," Engineering Applications of Artificial Intelligence, vol. 20, pp. 767-782, 2007.

[36] S. Syafiie, F. Tadeo, and E. Martinez, "Macro-actions in model-free intelligent control with application to $\mathrm{pH}$ control," IEEE Conference on Decision and Control pp. 2710-2715, 2005.

[37] Z. Zheng and N. Wang, "Model-free control based on neural networks," International Conference on Machine Learning and Cybernetics, vol. 4, pp. 2180-2183, 2002.

[38] T. P. Rose, G. G. Devadhas, and S. R. Rex, "Invention of a suitable controller for a non linear Chemical process," in Control, Instrumentation, Communication and Computational Technologies (ICCICCT), 2014 International Conference on, 2014, pp. 1462-1467.

[39] M. F. Zanil and M. A. Hussain, "Multivariable Adaptive Lyapunov Fuzzy Controller for pH Neutralisation Process," Computer Aided Chemical Engineering, vol. 37, pp. 1643-1648, 2015.

[40] E. H. Mamdani, "Application of fuzzy logic to approximate reasoning using linguistic synthesis," in Proceedings of the sixth international symposium on Multiple-valued logic, 1976, pp. 196-202.

[41] S. Menzl, M. Stühler, and R. Benz, "A self adaptive computer-based pH measurement and fuzzy-control system," Water Research, vol. 30, pp. 981-991, 1996. 